\title{
Research on the Mode Transformation and Innovation of Urban Planning Management
}

\author{
Ping Chen* \\ Construction Project Safety Station of Housing and Urban Rural Development Bureau, Cuiping, Yibin 644000, Sichuan \\ Province, China \\ *Corresponding author: Ping Chen, 2755765473@qq.cm

\begin{abstract}
As an important part of today's social development, cities are also an important guarantee for the improvement of people's living standards. As an important model of urban spatial layout, urban planning and management plays an important role in the development of urban economy, politics and culture. Based on this, this paper takes "urban planning and management" as the research theme, analyzes the existing planning model, and starts from the aspects of content and form, improves the pertinence and directivity of the existing planning system, so as to provide valuable reference for experts in the field.
\end{abstract}

Keywords: Urban planning; Management mode; Innovative thinking

Publication date: September 2021; Online publication: September 30, 2021

\section{Improve the urban construction planning and management system, promote the green development of cities}

Urban planning is the basis of urban development. In the new era, relevant departments should further improve the urban construction planning management system and light the beacon for urban development. Secondly, government departments should also actively play their guiding role, change their functions, reduce unnecessary administrative intervention, and ensure that the planning and management system is in line with the general trend of market economy development. At the same time, we should do a good job of information feedback, further analyze the planning information in this way, and provide favorable suggestions for relevant decision-makers. In addition, decision makers and specific staff should constantly improve their comprehensive business ability, analysis ability and management level, and adopt the working distance mechanism of wide area consultation, professional decision-making team and finally leading decision-making level to promote the think tank development of urban planning.

\section{Apply Internet technologies to land use management and improve management effectiveness}

Land use management is also the most important work of urban planning. In the context of the new era, natural space planning managers should make full use of modern scientific tools, combine professional and internet technology, and use comprehensive technical means to manage land space resources. On this basis, the natural resources and housing construction departments can also use small UAVs to establish urban land monitoring stations, build local ad hoc communication networks, and classify them according to the spatial attributes of urban land. Of course, relevant departments can also develop corresponding management information systems with the help of GIS technology. In addition, in order to further improve the efficiency of land use management, relevant departments should also create a transparent work management environment to regularly improve the management system, for example, from the following 
two levels:

\subsection{Improve project preparation}

Project preparation is an indispensable part of urban planning, and it also provides an open and transparent environment for urban planning. In the process of system implementation, the management publicity system is usually selected to enable each department to clarify its own responsibilities and specific approval process, publicize laws and regulations, and hold accountable the departments that do not implement management responsibilities, so as to make practical planning through the above measures.

\subsection{Building BIM information management}

In the process of urban planning, the staff of relevant departments can also use BIM technology for ground facilities planning and design, and pay attention to the construction of database on this basis. At the same time, the GIS technology operation interface has rich functions, including menus, parameters, icons and other information. In this case, the relevant managers can also adjust the parameters according to the actual needs to build a stable information system. In the application process of this technology, we found that this technology also has a significant advantage: it can trace historical data. In this way, it can also facilitate planners to adjust all kinds of data in time and give full play to the function and social value of land ${ }^{[1]}$.

\section{Pay attention to the management of human settlements and improve the quality of life}

\subsection{Pay attention to spatial comprehensive function planning}

\subsubsection{Urban and rural land space intensification}

As an important strategy for China's social development, the construction of ecological civilization is also an important guidance for the coordinated development of ecological environment and human society. In order to realize the "multi compliance and one" urban-rural space intensive development, the local government should change the traditional construction ideas, strengthen the urban space utilization rate, and explore a variety of space utilization modes according to the local population base and industrial characteristics, so as to provide a strong guarantee for the sustainable development of urban construction.

\subsubsection{Spatial networking of urban and rural land}

At present, in the process of adjusting the urban and rural spatial utilization mode, we should adhere to the policy of "people-oriented and sustainable development," actively explore a variety of spatial optimization modes, make dual connection and overall consideration, create a multi-level and multi gradient development pattern, realize the unified development of ecological civilization and urban construction, and ensure that people live and work in peace and contentment and the vigorous development of scientific and technological construction, form a benign urban spatial development framework.

\subsubsection{Urban and rural land space functionalization}

The essence of ecological civilization lies in the coordinated development of environment and society. Social environment and natural environment coexist and develop. Only by achieving the harmonious unity of nature and society can we build a sustainable urban ecological system. Urban construction should first plan the overall structure, make rational use of every inch of land, do not waste every resource, and use cities to drive rural areas to achieve integrated development.

\subsection{Dynamic planning and management of transportation system}

\subsubsection{Pay attention to traffic network planning}

As an important part of urban operation, traffic network has very important practical significance in improving the overall benefits of the city. Therefore, in the actual planning process, we should pay attention to the layout and division of traffic network, sort out the jurisdiction between roads and cities, optimize the 
spatial layout, give full play to the function of road traffic system, and make it better serve urban development. In view of the differences in the overall economic level and development status of the city, we should follow the planning principle of "advance, moderation, science and coordination," establish analysis and early warning models based on the reality of urban development, grid and radiate urban roads, improve road utilization, and lay the foundation for subsequent urban planning and construction.

\subsubsection{Building a multi-mode urban transportation system}

With the continuous development of social economy, the forms of public transport are becoming more and more diversified. The emergence of bus, subway and shared bicycle also marks the complexity and diversity of today's road system. At present, China's urban public transport network is often inflexible in the actual use process, the development of trunk lines is relatively perfect, the use frequency is high, and there are many uncertainties in the traffic conditions of auxiliary lines. In urban construction planning, road construction is the key planning content. We should focus on analyzing the local street road conditions and building a high-quality urban transportation system ${ }^{[2]}$.

\subsection{Carry out green space planning and management}

Green space management is an important part of urban planning management. In the process of management, relevant personnel should strictly abide by the guidelines ("the requirements of three districts and four lines"), on this basis, establish the concept of green management, strengthen the protection of urban green resources, reflect the regional and contemporary characteristics of the city, and make green space the highlight of urban landscape. In addition, the hierarchical characteristics of greening should be highlighted in the planning process, and a variety of greening methods should be introduced, such as vertical greening, roof garden, etc. In terms of plant selection, take into account the practicability and aesthetics of plants, create a dynamic three-dimensional space, and make the urban three-dimensional landscape plumper.

\section{Strengthen the overall planning and utilization of aboveground and underground space resources in key areas of urban and rural planning}

In the process of urban spatial planning, relevant personnel should put the aboveground and underground space planning in the first place and pay attention to the overall planning of the two. In this way, the aboveground and underground space pattern can also be effectively coordinated to make it in a relatively stable state. For example, in the process of traffic line planning, the personnel of transportation, planning and housing construction departments should give priority to the urban-rural express network, and longdistance roads can be planned in the underground space. In the process of spatial planning, we should also coordinate the development of horizontal and vertical directions, such as introducing vertical greening, improving the micro environment inside the traffic, and unifying the aboveground and underground space. In addition, some cities take some main roads of the city as key areas in the process of spatial planning, and lay underground comprehensive pipelines on this basis. In this way, it can also save aboveground space, increase the utilization rate of underground space resources, and coordinate aboveground and underground space. To transfer all urban infrastructure to the underground, its construction should be comprehensively organized and incorporated into an advanced operation mode ${ }^{[3]}$.

\section{Pay attention to urban-rural integration planning and promote the development of urban-rural integration}

\subsection{Create a planning system covering urban and rural areas}

Coordinated urban and rural development has always been the theme of urban development. Under the new era background, relevant departments can change the previous development concept, create a planning system covering urban and rural areas, take coordinated urban and rural development as the theme, and 
improve relevant development planning on this basis. In the planning process, we should also focus on the analysis of regional economic development and land use, change the previous planning concept and innovate the management system. Relevant personnel should also take the coordination of human land relations as the focus of development to form a complete planning system. Secondly, in the process of urban and rural planning, we should also pay attention to the coordination of urban and rural resources, further standardize the land use system, make efficient and intensive use of land, and realize the rational distribution of land resources. Thirdly, in the planning process, we should dynamically adjust the planning scheme in combination with the changing characteristics of urban population to form a certain spatial industrial structure and land layout. Increase publicity on the key points of rural revitalization, pay attention to the planning, construction and operation management of characteristic villages, ancient residential villages and historical and cultural villages, give priority to the development of human settlements, and build a bridge for the common development of urban and rural areas. Do a good job in the development system of infrastructure sharing, strengthen mutual benefit and exchange among regions, and promote the common development of urban and rural areas (Figure 1.) ${ }^{[4]}$.

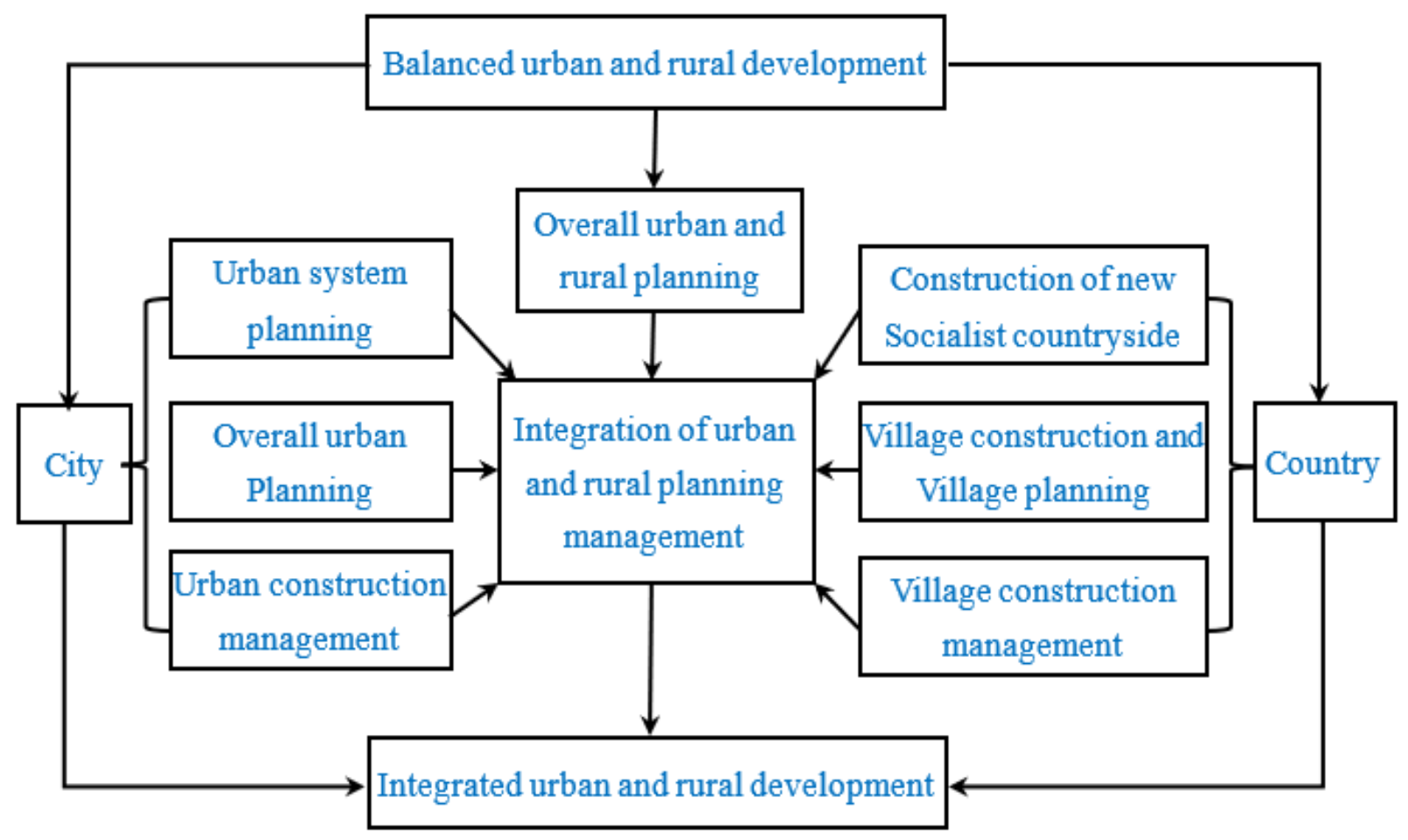

Figure 1. Urban-rural integration planning

\subsection{Apply high and new technology for management}

With the emergence of high and new technology, urban and rural planning and management has stepped into the expressway. Under the background of information age, relevant departments can carry out urban and rural planning and management with the help of high and new technology. For example, with the help of GIS and RS technology for spatial planning, these two technologies provide planners with visual space, which is conducive to assisting urban and rural planning management to make new progress. In addition, relevant personnel can also consult various data information with the help of these two technologies to reduce the error rate of decision-making. In addition, these two technologies also have the functions of statistics and monitoring, which can cooperate with other high and new technologies, such as remote sensing technology and geographic information technology, create a dynamic database, further improve the management efficiency and make the planning scheme more in line with the actual development 
characteristics.

To sum up, urban planning management is an important measure to promote urban ecological environment construction and overall urban and rural development. In the context of the new era, relevant personnel should reform the previous planning ideas, promote the green development of cities by improving the urban construction planning and management system, and apply Internet technology for land management to improve the effectiveness of management; Pay attention to the management of human settlements and improve the quality of life; Pay attention to urban-rural integration planning and promote the development of urban-rural integration. Take multiple measures at the same time, adhere to the ecological space of giving priority to the development of human settlements, and promote the sustainable development of cities in China.

\section{Disclosure statement}

The author declares no conflict of interest.

\section{References}

[1] Ren X, Lv M, 2017, Ideas and Strategies for Fine Management of Urban Planning from the Perspective of Urban Design. Planner, 33(10): 24-28.

[2] Yang T, 2017, Spatial Syntax: Urban Planning Management based on Spatial Form. Urban Planning, 41(02): 27-32.

[3] Wu S, 2013, Research on Problems in Urban Planning and Management in China. Henan University.

[4] Gideon SG, Toshio O, 2005, Geo Space Urban Design. 